\title{
Stability Assessment of an Airflow Distorted Military Engine's FAN
}

T Triantafyllou*, T Nikolaidis, M Diakostefanis, P Pilidis Cranfield University, School of Aerospace, Transport and Manufacturing, College Rd, Cranfield, Bedford MK43 OAL, United Kingdom

\section{ABSTRACT}

Military aircraft are often subjected to severe flight maneuvers with high Angles of Attack (AOA) and Angles of Sideslip (AOSS). These flight attitudes induce non-uniformity in flow conditions to their gas turbine engines which may include distortion of inlet total pressure and total temperature at the Aerodynamic Interface Plane (AIP). Operation of the downstream engine's compression system may suffer reduced aerodynamic performance and stall margin, and increased blade stress levels. The present study presents a methodology of evaluating the effect of inlet flow distortion on the engine's fan stability. The flow distortion examined was induced to the AIP by means of changing the aircraft's flight attitude. The study is based on the steady state flow results from 27 different flight scenarios that have been simulated in CFD. As a baseline model geometry an airframe inspired by the General Dynamics/LMAERO F-16 aircraft was chosen, which has been exposed to subsonic incoming airflow with varying direction resembling thus different aircraft flight attitudes. The results are focused on the total pressure distribution on the engine's (AIP) face and how this is manifested at the operation of the fan. Based on the results, it was concluded that the distorted conditions cause a shift of the surge line on the fan map, with the amount of shift to be directly related to the severity of these distorted conditions. The most severe flight attitude in terms of total pressure distortion, among the tested ones, caused about 7\% surge margin depletion comparing to the undistorted value.

\section{KEYWORDS}

Fan stability, surge margin, total pressure distortion, fan distorted surge line, military engine

$\begin{array}{llll}\text { NOMENCLATURE } & \mathrm{p}[\mathrm{Pa}] & \text { Static Pressure } \\ \text { Symbols } & & \mathrm{T}[\mathrm{K}] & \text { Total Temperature } \\ \mathrm{M}[-] & \text { Mach number } & \mathrm{t}[\mathrm{K}] & \text { Static Temperature } \\ \mathrm{N}[\mathrm{rpm}] & \text { Rotational Speed } & \mathrm{W}[\mathrm{Kg} / \mathrm{s}] & \text { Mass Flow Rate } \\ \mathrm{P}[\mathrm{Pa}] & \text { Total Pressure } & & \end{array}$

*Corresponding author:

School of Aerospace, Transport and Manufacturing,

Cranfield University,

Cranfield, Bedfordshire, UK

email: t.triantafillou@cranfield.ac.uk 
Z [-] Surge Margin

Parameter

\section{Greek Symbols}

$\Delta[-] \quad$ Difference and Loss

$\theta\left[{ }^{\circ}\right] \quad$ Circumferential Angle

\section{Abbreviations}

AIP Aerodynamic Interface Plane

AOA Angle of Attack

AOSS Angle of Side Slip

CFD Computational Fluid Dynamics

CM Corrected Mass Flow

DP Design Point

NDMF Non Dimensional Mass Flow

OD Off Design

OPR Overall Pressure Ratio

PCN Relative Rotational Speed

\section{INTRODUCTION}

Military aircraft gas turbine engines are often subjected to non-uniform inflow conditions due to the flight maneuvers the aircrafts accomplish ${ }^{(1)}$. These flow non-uniformities may include distortion of total pressure and total temperature. Total pressure distortion occurs when there is a nonuniform total pressure distribution at the fan face and arises as a result of the flow interacting adversely with the airframe upstream of the $\operatorname{fan}^{(2)}$. Similarly, non uniform distribution of the total temperature at the same area denotes the presense of total temperature distortion and may occur due to the ingestion of exhaust gases from a leading aircraft or a fired missile ${ }^{(3)}$.

As these distorted airflow conditions reach the Aerodynamic Interface Plane (AIP) which is the
PRDS Distorted Surge Pressure Ratio

PRF Pressure Recovery Factor

PRS Surge Pressure Ratio

PR Pressure Ratio

PW Pratt \& Whitney

SFC Specific Fuel Consumption

SLS Sea Level Static

SM Surge Margin

\section{Subscripts}

c Circumferential

h Hub

L Low Pressure Shaft

r Radial

t Tip

dist Distorted

boundary between the intake and the engine, they start affecting the operation of the entire powerplant.

More specificaly, the downstream compression system that first experiences the distorted airflow may suffer reduced aerodynamic performance and stall margin ${ }^{(4)}$, and increased blade stress levels ${ }^{(5)}$. Also the output of the engine in terms of resulted net thrust is affected by the variations of the airflow characteristics due to distortion.

\section{REVIEW OF PRIOR INVESTIGATIONS}

The most concentrated work on flow distortion was originally (pre1960) carried out on the first generation of lift engines and compressors (RB 108 and RB 1455) where the V.T.O.L application called 
for the toleration of extremely high distortion levels ${ }^{(6)}$.

The first basic work that started to examine compression system stability and dynamics as a function of inlet total pressure variation was that of Pearson and McKenzie (7), who first proposed the parallel compressor theory. According to that theory, a compression system under the influence of a total pressure distortion could be treated as two compressors operating in parallel and which are assumed to discharge to the same static pressure.

Some years later, Reid ${ }^{[6]}$ showed that for small circumferential extent inlet distortion patterns, the parallel compressor model did not hold true.

Several years later, Kurzke (8) described how changes in performance due to the inlet pressure and temperature distortion can be calculated with an overall engine simulation that employed an integrated parallel compressor model.

Currently, the airframe-propulsion integration process is handled by an established methodology that has been derived by consensus of industry and government experts ${ }^{(9),(10)}$ over the last 37 years and reported by the Society of Automotive Engineers (SAE) in an Aerospace Recommended Practice namely the ARP- $1420^{(11)}$. This document was developed by the SAE Technical Committee, S-16 (Turbine Engine Inlet Flow Distortion), and along with its companion document, AIR $1419^{(12)}$ they set the guidelines for the intake/engine compatibility as far as the total pressure distortion is concerned.

In the present study the effect of total pressure distortion on the fan stability has been assessed following the guidelines of ARP 1420 i.e. using distortion descriptors. The calculated distortion descriptors have been then correlated to the depletion of the fan surge margin through the loss in surge pressure ratio and in that way the effect of the distorted flow on the fan stability has been evaluated.

The work presented herein is a part of a greter research effort to evaluate the effect of distorted flow on an installed gas turbine engine's performance $^{(13)}$.

\section{NUMERICAL SIMULATION}

The present study provides a methodology for the evaluation of the total pressure distortion effect on the operation of the engine's fan.

For the purpose of this study, a military aircraft, inspired by the General-Dynamics/LMAERO F-16 airframe assumed to be equipped with a Pratt and Whitney F100-PW229 equivalent gas turbine engine, was selected as a baseline set of airframe-engine.

Patterns of distribution of the total pressure at the Aerodynamic Interface Plane (AIP) have been obtained through CFD simulations where the flow over a full scale military aircraft 
with an active intake was numerically resolved ${ }^{(14)}$.

Different flight attitudes were considered by changing accordingly the direction of the incoming flow in the computational domain.

The tested conditions refered to 27 different aircraft flight scenarios, all at $20000 \mathrm{ft}$ altitude (table 1):

- three different flight Mach numbers: $0.35 \mathrm{M}, 0.6 \mathrm{M}$ and $0.85 \mathrm{M}$

- nine combinations of Angles of Attack (AOA) and Angles of Sideslip (AOSS) at each one of the above tested flight Mach numbers (AOA and AOSS varied in the range of 0 to 16 degrees).

The calculated distorion patterns were in the form of total pressure contours, as shown in fig.1. In this figure, the different colouring denotes the variation of the total pressure and the bluish coloured areas represent the lowest pressure regions. In Figure $1 b$ the total pressure values at the AIP have been normalized against the value of total pressure at the intake's entry. In that way graphical view of the achieved intake pressure recovery for this flight attitude can be obtained.
Table 1 Test cases matrix Altitude 20,000ft

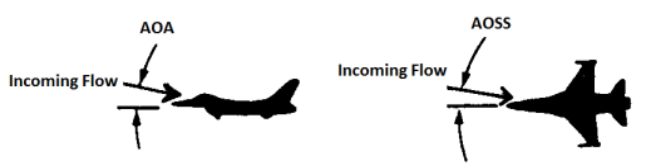

\begin{tabular}{|c|c|c|c|}
\hline Case & $\begin{array}{c}\text { Flight } \\
\text { Speed } \\
\text { (M) }\end{array}$ & $\begin{array}{l}\text { AOA } \\
\text { (deg) }\end{array}$ & $\begin{array}{l}\text { AOSS } \\
\text { (deg) }\end{array}$ \\
\hline 1 & 0.35 & 0 & 0 \\
\hline 2 & 0.35 & 8 & 0 \\
\hline 3 & 0.35 & 16 & 0 \\
\hline 4 & 0.35 & 0 & 8 \\
\hline 5 & 0.35 & 0 & 16 \\
\hline 6 & 0.35 & 8 & 8 \\
\hline 7 & 0.35 & 8 & 16 \\
\hline 8 & 0.35 & 16 & 8 \\
\hline 9 & 0.35 & 16 & 16 \\
\hline 10 & 0.6 & 0 & 0 \\
\hline 11 & 0.6 & 8 & 0 \\
\hline 12 & 0.6 & 16 & 0 \\
\hline 13 & 0.6 & 0 & 8 \\
\hline 14 & 0.6 & 0 & 16 \\
\hline 15 & 0.6 & 8 & 8 \\
\hline 16 & 0.6 & 8 & 16 \\
\hline 17 & 0.6 & 16 & 8 \\
\hline 18 & 0.6 & 16 & 16 \\
\hline 19 & 0.85 & 0 & 0 \\
\hline 20 & 0.85 & 8 & 0 \\
\hline 21 & 0.85 & 16 & 0 \\
\hline 22 & 0.85 & 0 & 8 \\
\hline 23 & 0.85 & 0 & 16 \\
\hline 24 & 0.85 & 8 & 8 \\
\hline 25 & 0.85 & 8 & 16 \\
\hline 26 & 0.85 & 16 & 8 \\
\hline 27 & 0.85 & 16 & 16 \\
\hline
\end{tabular}




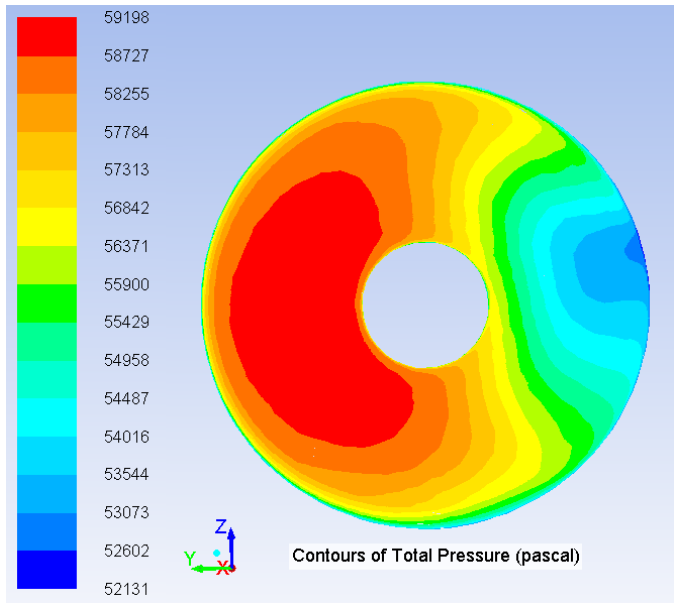

(a)

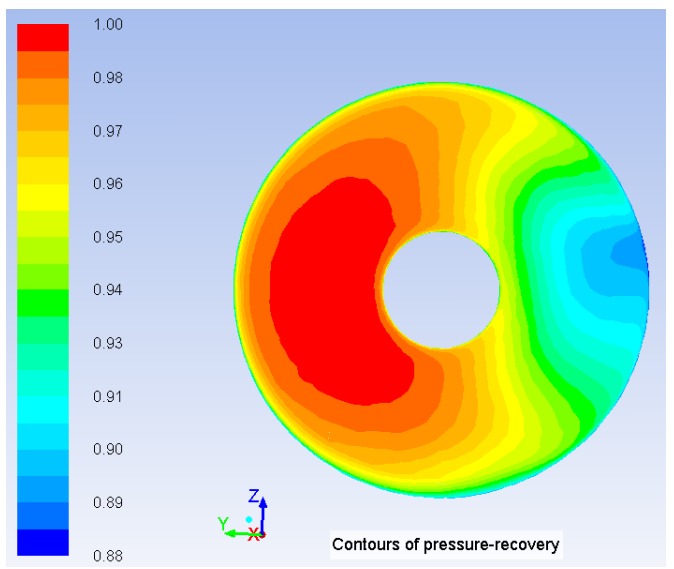

(b)

Fig. 1 Total Pressure Profile at the AIP (a) and Normalized Values of Pressure against the Intake Entry Total Pressure (b) for the $0.6 \mathrm{M}$ Flight with $8^{\circ} \mathrm{AOA}$ and $16^{\circ}$ AOSS $^{(14)}$

\section{TURBOMATCH SCHEME}

In the present study fan 's stability was assessed having as a frame of reference one of the automatically scaled default maps from Turbomatch database, since no data on the baseline engine's fan map were accessible. Actual compressor maps are Original Equipment Manufacturers' (OEM) proprietary information arising from costly rig tests and they can hardly be located in the open literature.

Turbomatch is a Cranfield University gas turbine engine simulation software, which was initially developed by Palmer (9) and it facilitates design point (DP), off-design (OD) and transient operation performance calculations for aero (civil and military), industrial and marine engines. 


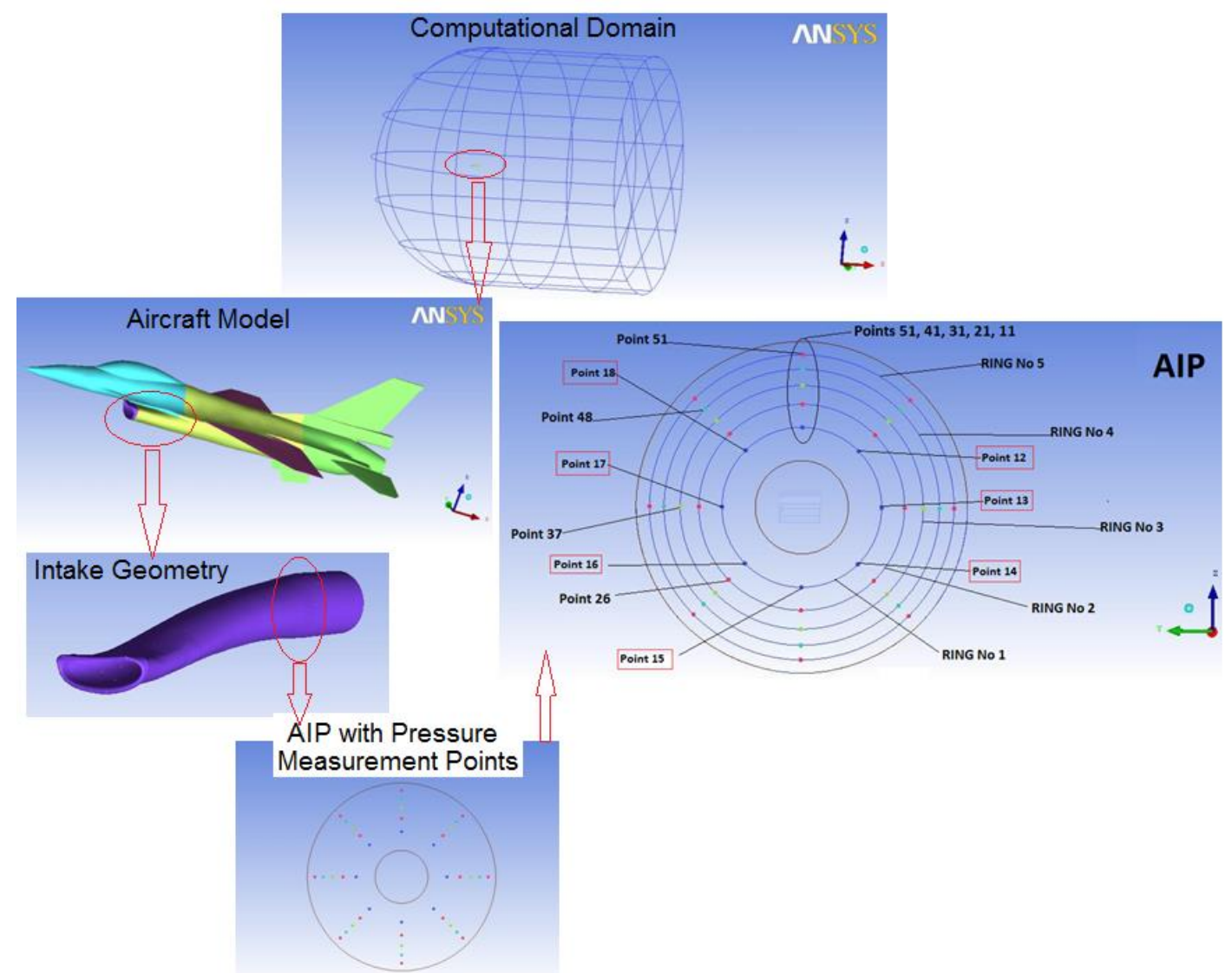

Fig. 2 Steps of the Airflow Numerical Simulation ${ }^{(21)}$

In this software, by means of "codewords", various preprogrammed routines known as "bricks" can be called up to simulate the action of the different engine's components. The gas turbine performance is calculated by using component characteristic maps for compressors, combustion chambers, turbines (both compressor turbines and free turbines) and a map providing the velocity coefficient for exhaust nozzles.

Turbomatch, includes a large number of simulation capabilities, such as degraded component performance, use of different fuels (kerosene, natural gas, hydrogen, diesel and biofuels), variable compressor and turbine geometry, humidity effects, water injection and ingestion effects ${ }^{(16)}$ and its results have been compared and validated against commercially sensitive experimental and test data ${ }^{(17),(18)}$.

\subsection{Baseline Engine's Fan Map}

Table 2 below presents some of the basic parameters of the baseline engine used in the DP performance calculations-(SLS conditions) . 
Table 2

Baseline Engine's DP Parameters

\begin{tabular}{|l|l|}
\hline Parameter & Value \\
\hline Intake Pressure Recovery & 0.99 \\
\hline Mass Flow Rate (Kgr/s) & 114.1 \\
\hline Bypass Ratio & 0.36 \\
\hline Fan Pressure Ratio & 3.2 \\
\hline Fan Efficiency & 0.82 \\
\hline HPC Pressure Ratio & 10.6 \\
\hline HPC Efficiency & 0.85 \\
\hline TET (K) & 1750 \\
\hline HPT Efficiency & 0.87 \\
\hline LPT Efficiency & 0.88 \\
\hline
\end{tabular}

Table 3 presents the baseline engine's design point performance data that were used for the validation of the performance simulation model. In the same table the respective values resulted from the Turbomatch simulation model have been also quoted. The derived percentage difference between these two sets of values gives credit to the simulation model used in the baseline engine's performance calculations.

Also fig. 3 presents a layout of the baseline engine's components ("bricks" in Turbomatch) which was primarily used in the creation of the engine's simulation model. On this figure and for the components that they are not self explanatory:

- MIXEES, refers to the "brick" that Turbomatch uses to calculate the outlet conditions resulting from the mixing of two flows with given inlet conditions and with no allowance for total pressure change.

- MIXFUL, refers to the "brick" that Turbomatch uses to calculate the outlet conditions resulting from mixing of two flows with given inlet conditions, with full allowance for total pressure change resulting from momentum balance.

- PREMAS, refers to the "brick" that Turbomatch uses to calculate the outlet conditions from a component such as a splitter, bleed, bypass duct or jet pipe, given the absolute and/or relative changes of mass flow and total pressure.

- DUCTER, refers to the "brick" that Turbomatch uses to calculate the outlet conditions from a duct, given the inlet conditions and relative total pressure loss; also, if called for, to calculate the reheat fuel flow, given the outlet total temperature and combustion efficiency.

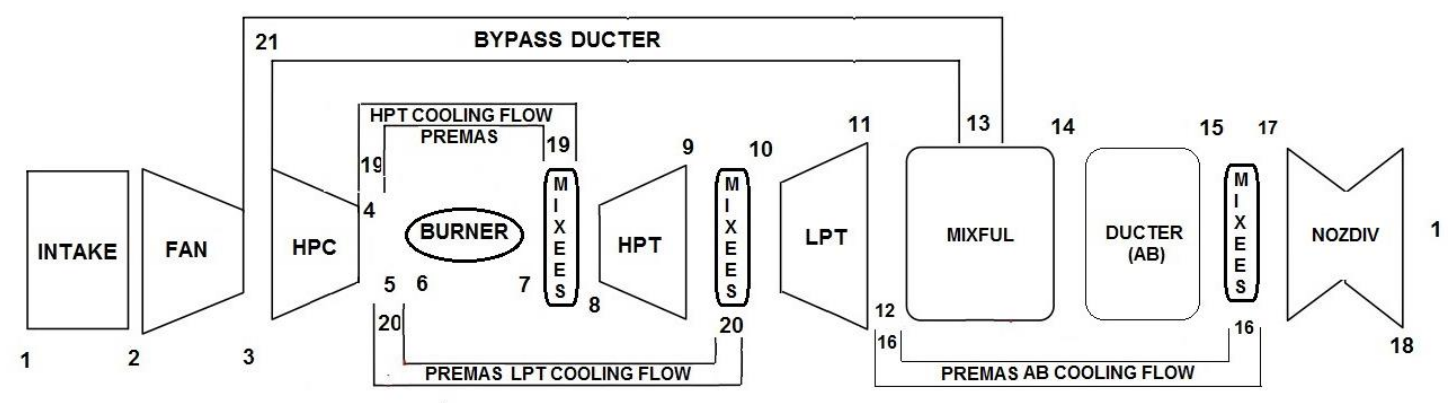


Fig. 3 Sketch of the F100-PW-229 Turbofan Engine's Components

Table 3 The Baseline Engine's Design Point Performance Data (19), (20)

\begin{tabular}{|l|c|c|c|}
\hline & Literature Data $^{(13),(14)}$ & $\begin{array}{c}\text { Simulation } \\
\text { Results }\end{array}$ & Percentage Difference \\
\hline Dry Thrust (N) & 79200 & 79317 & 0.15 \\
\hline SFC (lb/hr/lbf) & 0.74 & 0.72 & 2.74 \\
\hline Dry Fuel Flow (Kg/s) & 1.67 & 1.62 & 3.04 \\
\hline
\end{tabular}

Figure $4 a$ presents the resulted map that was called out from the Turbomatch database and that it is assumed to cover the operation of the under examination fan. The baseline engine's design point (DP) which is static conditions) is also located on this map.

Figure $4 \mathrm{~b}$ presents the map of the efficiency lines, where it can be seen how close to the maximum efficiency the DP is located.

assumed to be T/O - SLS (sea level

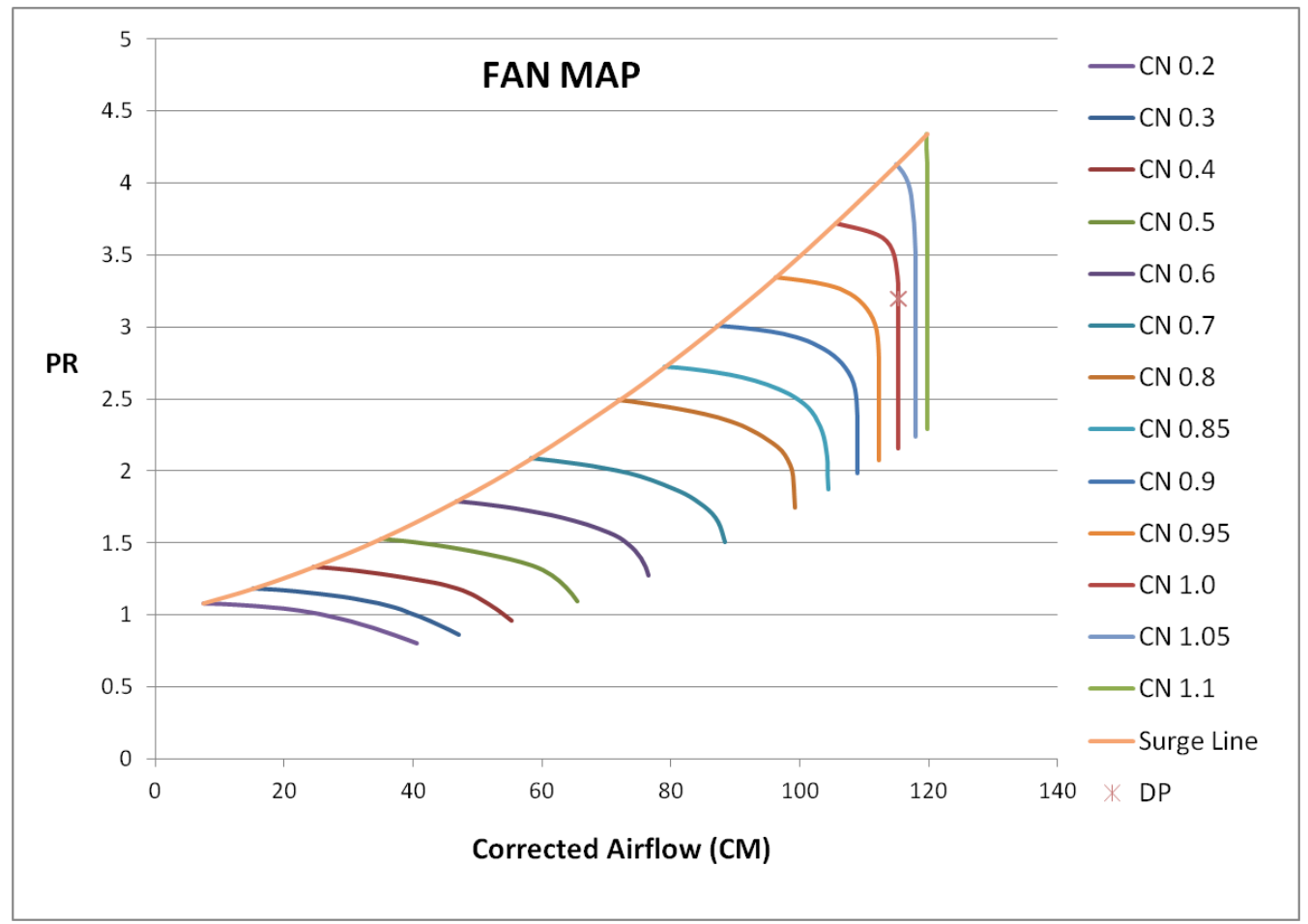

(a) 


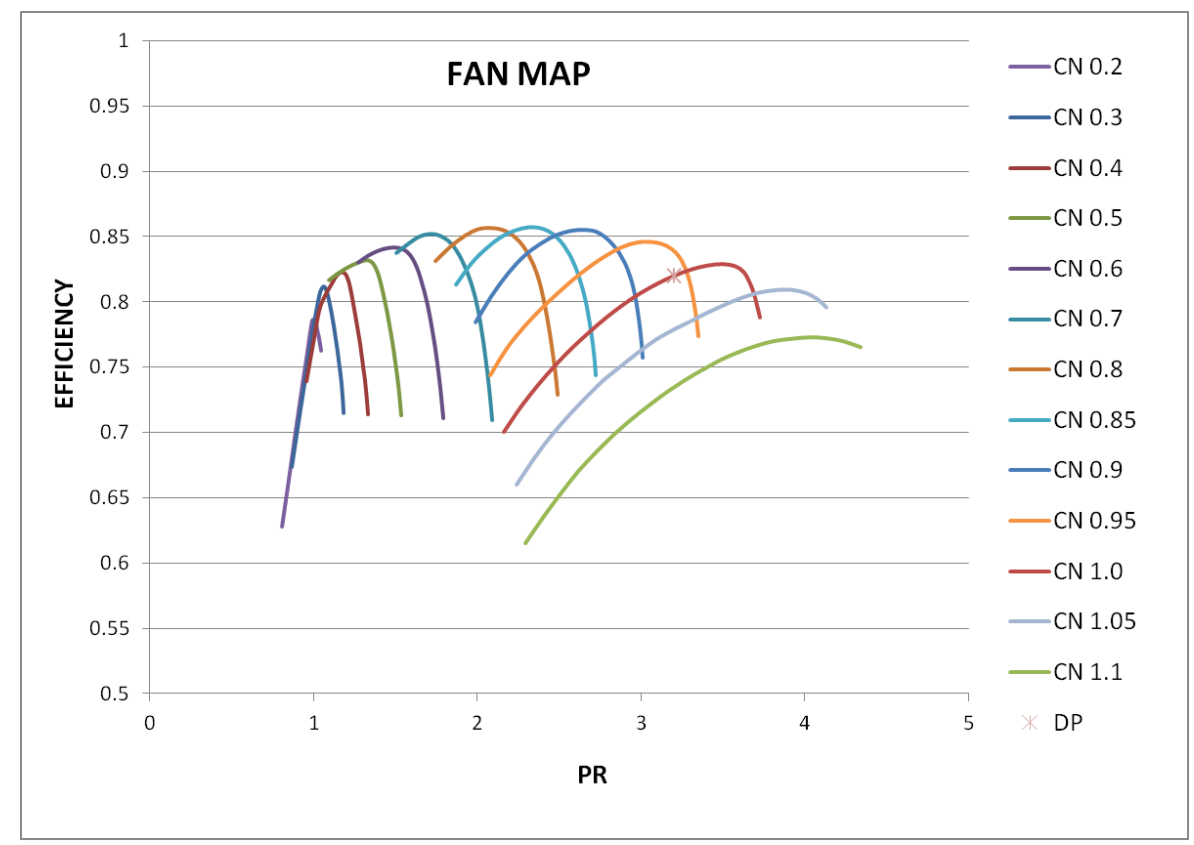

(b)

Fig. 4 Fan Map with the DP (a) and Efficiency Lines (b)

\section{FAN STABILITY ASSESSMENT}

Due to the changes in the aircraft's flight attitude along with the fact that the engine is highly embedded into the airframe, the airflow that reaches the engine's face is not uniform at all.

The first engine's component that experiences these distorted conditions is the fan. Depending on the severity of the distortion, the stability of the fan may be threatened i.e. its operating point may move beyond the surge line on its characteristics map.

In order to create a frame of reference in the fan stability assessment calculations three off design (OD) cases were run in Turbomatch, simulating the performance of the uninstalled engine at the environmental conditions of 20000ft altitude; Mach 0.35, 0.6 and 0.85 .
At these OD calculations a rather high intake pressure recovery was chosen (0.99) denoting the uninstalled status of the engine i.e. the effect of the intake on the engine's performance was not taken into consideration.

Also, the FAN rotational speed (PCN) was used as the driving parameter and its value was iteratively adjusted until for each baseline condition the resulted mass flow entering the engine, corresponded to the $100 \%$ of the design corrected airflow (CM).

The rationale underlying this selection was twofold:

- To create the same inflow conditions in all cases, for comparison purposes.

- To control one of the engine's basic performance parameters 
simulating thus the action of a control system that monitors the FAN rotational speed.

Table 4 presents the FAN PCN values that resulted in the same corrected mass flow (CM) entering the engine for the three OD cases.

Table $4 \quad$ Turbomatch Results Showing the Constant CM

\begin{tabular}{|c|c|c|c|}
\hline Mach & CM & PCN & $\begin{array}{c}\text { NET } \\
\text { THRUST } \\
\text { (KN) }\end{array}$ \\
\hline $\begin{array}{c}0.00 \\
\text { (DP) }\end{array}$ & 115.28 & 1.0 & 79.3 \\
\hline $\begin{array}{c}0.35 \\
\text { (OD) }\end{array}$ & 115.28 & 0.940 & 33.8 \\
\hline $\begin{array}{c}0.60 \\
\text { (OD) }\end{array}$ & 115.28 & 0.961 & 36.6 \\
\hline $\begin{array}{c}0.85 \\
\text { (OD) }\end{array}$ & 115.28 & 0.993 & 43.1 \\
\hline
\end{tabular}

These conditions were the baseline for the FAN stability assessment and the Surge Margin (SM) was defined for each one of them, following the guidelines of SAE ARP $1420^{(11)}$. So with reference to fig. 5 ,

$$
\left.S M=\frac{P R_{1}-P R_{0}}{P R_{0}} \times 100 \quad \text { (eq. } 1\right)
$$

When eq. 1 was applied to the baseline conditions, the SM results presented in table 5 were obtained.

Table 5 FAN Surge Margin for the Baseline Conditions

\begin{tabular}{|c|c|c|c|c|}
\hline $\begin{array}{c}\text { Baseline } \\
\text { Points } \\
\text { (Flight } \\
\text { Mach) }\end{array}$ & PRO & CM & PR1 & SM \\
DP (SLS) & 3.200 & 115.28 & 4.148 & 29.62 \\
\hline $0.35 M$ & 3.192 & 115.28 & 4.148 & 29.95 \\
\hline
\end{tabular}

\begin{tabular}{|c|c|c|c|c|}
\hline $0.6 \mathrm{M}$ & 3.195 & 115.28 & 4.148 & 29.82 \\
\hline $0.85 \mathrm{M}$ & 3.199 & 115.28 & 4.148 & 29.66 \\
\hline
\end{tabular}

As it has already been mentioned, for the calculation of the baseline conditions the engine was considered uninstalled and as such the airflow that reached the engine's face was rather uniform. In case of an installed engine though, the airframe affects the quality of the airflow that the engine experiences.

In the context of the current study, each one of the 27 CFD tested flight attitudes induced a total pressure distortion into the engine's face (AIP). This pressure distortion was quantified through the calculation of distortion descriptors in the way that has been described in detail in Triantafyllou et al (21)

These distortion parameters can be correlated to the Loss in Surge Pressure Ratio ( $\triangle P R S$ ) in the way suggested by SAE AIR $1419^{(12)}$.

$\triangle P R S$ is the loss in surge pressure ratio due to inlet distortion, normalized by the undistorted surge pressure ratio ${ }^{(11)}$. With reference to fig. $5^{(11)}$,

$$
\triangle P R S=\frac{(P R 1-P R D S)}{P R 1} \times 100 \quad \text { (eq.2) }
$$

This loss may be considered as a combined effect caused by both the circumferential ( $\triangle \mathrm{PRSC}$ ) and radial ( $\triangle \mathrm{PRSr}$ ) components of distortion. So,

$$
\triangle P R S=\triangle P R S_{c}+\triangle P R S_{r} \quad \text { (eq. 3) }
$$


The circumferential component ( $\triangle \mathrm{PRSC}$ ) can be correlated to the distortion descriptors shown in the following equation ${ }^{(12)}$,

$$
\Delta P R S_{c}=\left[\sum_{i=1}^{N} a_{i} K_{c}\left(\frac{\Delta P C}{P}\right)_{i}\left(\frac{\theta_{i}}{180}\right)\left(\frac{1}{M P R}\right)_{i}\right] \times 100
$$

where, $\mathbf{N}$ is the number of the total pressure measurement rings on the engine's face plane, as they appear in fig. 2 above, $\quad \boldsymbol{\alpha}_{\boldsymbol{i}}$ is the weighting factor for ring $i, \mathbf{K}_{\mathbf{c}}$ is the average circumferential sensitivity, determined empirically from tests with 180 degrees classical inlet distortion screens $^{(12)}, \quad\left(\frac{\Delta P \boldsymbol{c}}{\boldsymbol{P}}\right)_{\boldsymbol{i}}$ is the circumferential distortion intensity of ring $i, \boldsymbol{\theta}_{i}$ is the circumferential extent of distortion in ring $i$ in degrees and $\mathbf{M P R}_{\mathbf{i}}$ is the multiple per revolution element for ring $i$.

The loss in surge pressure ratio because of radial distortion $\left(\triangle P R S_{r}\right)$ is the highest among the losses evaluated for the hub $\left(\triangle P R S_{h}\right)$ and tip $\left(\triangle P R S_{t}\right)$ regions. These are defined in equations 5 and 6 respectively ${ }^{(12)}$ :

$$
\Delta P R S_{h}=\left\{\left[\sum_{i=1}^{2} 1 / 2 K_{r}\left(\frac{\Delta P R}{P}\right)_{i}\right]+C_{h}\right\} \times 100
$$

where, $\mathbf{K}_{\mathbf{r}}$ is the average radial sensitivity determined empirically (12),$\left(\frac{\Delta P R}{P}\right)_{i}$ is the radial distortion intensity of ring $\mathrm{i}, \mathbf{C}_{\mathbf{h}}$ is the radial offset term for the hub.

$\Delta P R S_{t}=\left\{\left[\sum_{i=N-1}^{N} 1 / 2 K_{r}\left(\frac{\Delta P R}{P}\right)_{i}\right]+C_{t}\right\} \times 100$ (eq.6)

where, $\mathbf{C}_{\mathbf{t}}$ is the radial offset term for the tip.

Based on the distortion descriptor results obtained in Triantafyllou et al ${ }^{(21)}$, the loss in surge pressure ratio ( $\triangle \mathrm{PRS})$ for the examined flight attitudes are presented in table 6 . It is clarified that the flight attitudes with negative values of $\triangle P R S$ result in an increase in surge pressure ratio (relative to the uninstalled FAN) because in accordance with eq. 3 above, in these cases the absolute value of the radial distortion component was greater than that of the circumferential distortion and since the radial distortion was negative in these cases the outcome of eq. 3 was also negative. This practically infers that in the cases which resulted in negative values of $\triangle P R S$ the gain in surge margin due to radial distortion more than offsets the loss in surge margin due to circumferential distortion.

In conclusion, the Total Pressure distortion causes a shift to the baseline FAN surge line and its new position for each flight attitude can be estimated by taking into account the $\triangle P R S$ that has been calculated in eq. 2 . So, the distorted surge PR (PRDS) for each tested flight attitude, was calculated from the eq. 7 below ${ }^{(12)}$,

$$
P R D S=P R_{1}-\frac{P R_{1} \times \triangle P R S}{100} \quad \text { (eq. 7) }
$$


where PR1 is the undistorted Surge PR of the baseline condition.

Then, with reference to fig. $5^{(11)}$, the distorted Surge Margin ( $\left(\mathrm{SM}_{\text {dist }}\right)$ for each case can be also defined.

$S M_{\text {dist }}=\frac{P R D S-P R_{0}}{P R_{0}}($ eq. 8)

where $P R_{0}$ is the operating $P R$ of the baseline condition.

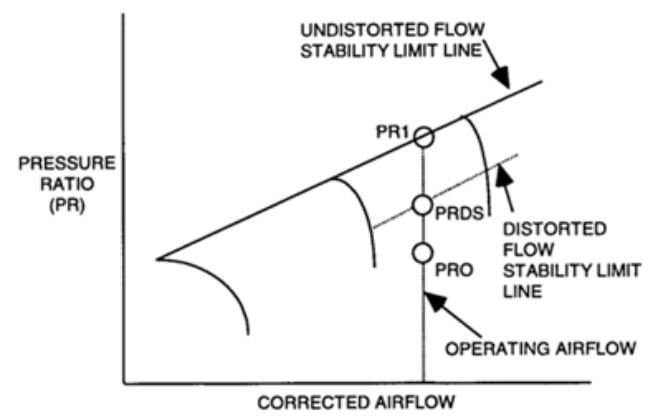

Fig. 5 Definition of Surge Margin ${ }^{(11)}$

Table 6 presents the estimated $S M_{\text {dist }}$ results for each tested case. When observing these results it becomes obvious that none of the examined flight conditions threatens the stability of the FAN i.e. the $\mathrm{SM}_{\text {dist }}>$ 0 in all cases.

\section{SURGE MARGIN DEPLETION}

The most severe attitude among the tested ones, in terms of loss in surge pressure ratio ( $\triangle P R S$ ), is that at $0.85 \mathrm{M}$ with $0^{\circ} \mathrm{AOA}$ and $16^{\circ}$ AOSS.
Based on the $\mathrm{SM}_{\text {dist }}$ result that corresponds to this flight attitude (table 6), it can be concluded that the operating point of the engine at these specific conditions is far away from the stability limit line of the FAN.

Both the mass flow rate that enters the intake at this flight attitude and the intake pressure recovery have been CFD calculated at $74.59 \mathrm{Kgr} / \mathrm{s}$ and 0.945 respectively ${ }^{(14)}$.

The performance of the engine for this specific flight attitude may be calculated by entering the mass flow rate and intake pressure recovery values, mentioned above, into the baseline engine's performance simulation model. Also the engine's fan map may be derived when plotting the resulted $C M$ and PR data for each speed line.

Figure 6 ( $a$ and $b$ ) presents the engine's fan map with the distorted surge line that refers to the flight attitude of $0.85 \mathrm{M}$ with $0^{\circ} \mathrm{AOA}$ and $16^{\circ}$ AOSS. Comparing to the undistorted surge line, the distorted one presents a shift towards the direction of SM depletion. The amount of shift reflects how the surge line of the fan was affected by these distorted conditions. 
Table 6 FAN Stability Assessment Results

\begin{tabular}{|c|c|c|c|c|c|c|c|c|c|}
\hline \multicolumn{10}{|c|}{ 0.35M FLIGHT ATTITUDES } \\
\hline AOA_AOSS & $0 \_0$ & $0 \_8$ & 0_16 & 8_8 & 8_16 & $16 \_8$ & 8_0 & $16 \_0$ & 16_16 \\
\hline $\begin{array}{l}\text { PRS } \\
\text { (PR1 in fig.5) }\end{array}$ & \multicolumn{9}{|c|}{4.148} \\
\hline$\triangle \mathrm{PRS}$ & -1.421 & -0.663 & 0.937 & -0.596 & 0.567 & 0.263 & -0.571 & 0.310 & 0.806 \\
\hline PRDS & 4.207 & 4.176 & 4.109 & 4.173 & 4.124 & 4.137 & 4.172 & 4.135 & 4.115 \\
\hline SMdist & 31.797 & 30.811 & 28.733 & 30.724 & 29.213 & 29.608 & 30.692 & 29.548 & 28.902 \\
\hline \multicolumn{10}{|c|}{ 0.6M FLIGHT ATTITUDES } \\
\hline AOA_AOSS & 0_0 & $0 \_8$ & 0_16 & 8_8 & 8_16 & $16 \_8$ & 8_0 & $16 \_0$ & 16_16 \\
\hline $\begin{array}{l}\text { PRS } \\
\text { (PR1 in fig.5) }\end{array}$ & \multicolumn{9}{|c|}{4.148} \\
\hline$\triangle \mathrm{PRS}$ & -0.791 & -0.274 & 1.520 & -0.477 & 0.764 & -0.325 & -1.015 & -0.308 & 0.639 \\
\hline PRDS & 4.181 & 4.159 & 4.085 & 4.168 & 4.116 & 4.161 & 4.190 & 4.161 & 4.122 \\
\hline SMdist & 30.854 & 30.184 & 27.855 & 30.447 & 28.836 & 30.250 & 31.145 & 30.228 & 28.999 \\
\hline \multicolumn{10}{|c|}{ 0.85M FLIGHT ATTITUDES } \\
\hline AOA_AOSS & $0 \_0$ & $0 \_8$ & 0_16 & 8_8 & 8_16 & $16 \_8$ & 8_0 & $16 \_0$ & 16_16 \\
\hline $\begin{array}{l}\text { PRS } \\
\text { (PR1 in fig.5) }\end{array}$ & & & & & 4.148 & & & & \\
\hline$\triangle \mathrm{PRS}$ & -0.491 & -0.036 & 1.544 & -0.596 & 0.550 & -0.731 & -0.658 & -0.731 & 0.159 \\
\hline PRDS & 4.168 & 4.150 & 4.084 & 4.173 & 4.125 & 4.178 & 4.175 & 4.178 & 4.141 \\
\hline SMdist & 30.302 & 29.713 & 27.664 & 30.438 & 28.952 & 30.613 & 30.519 & 30.613 & 29.459 \\
\hline
\end{tabular}

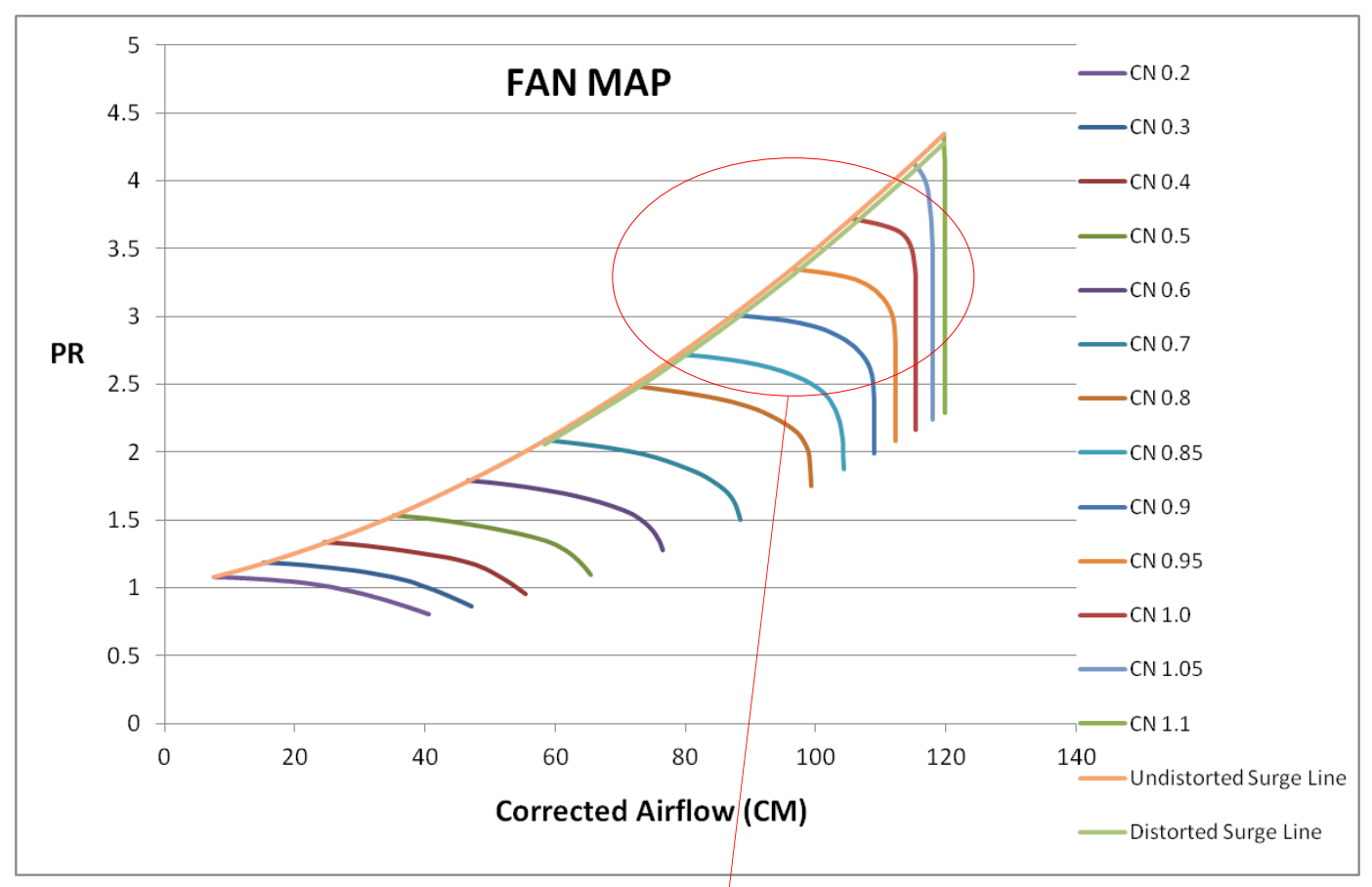

(a) 


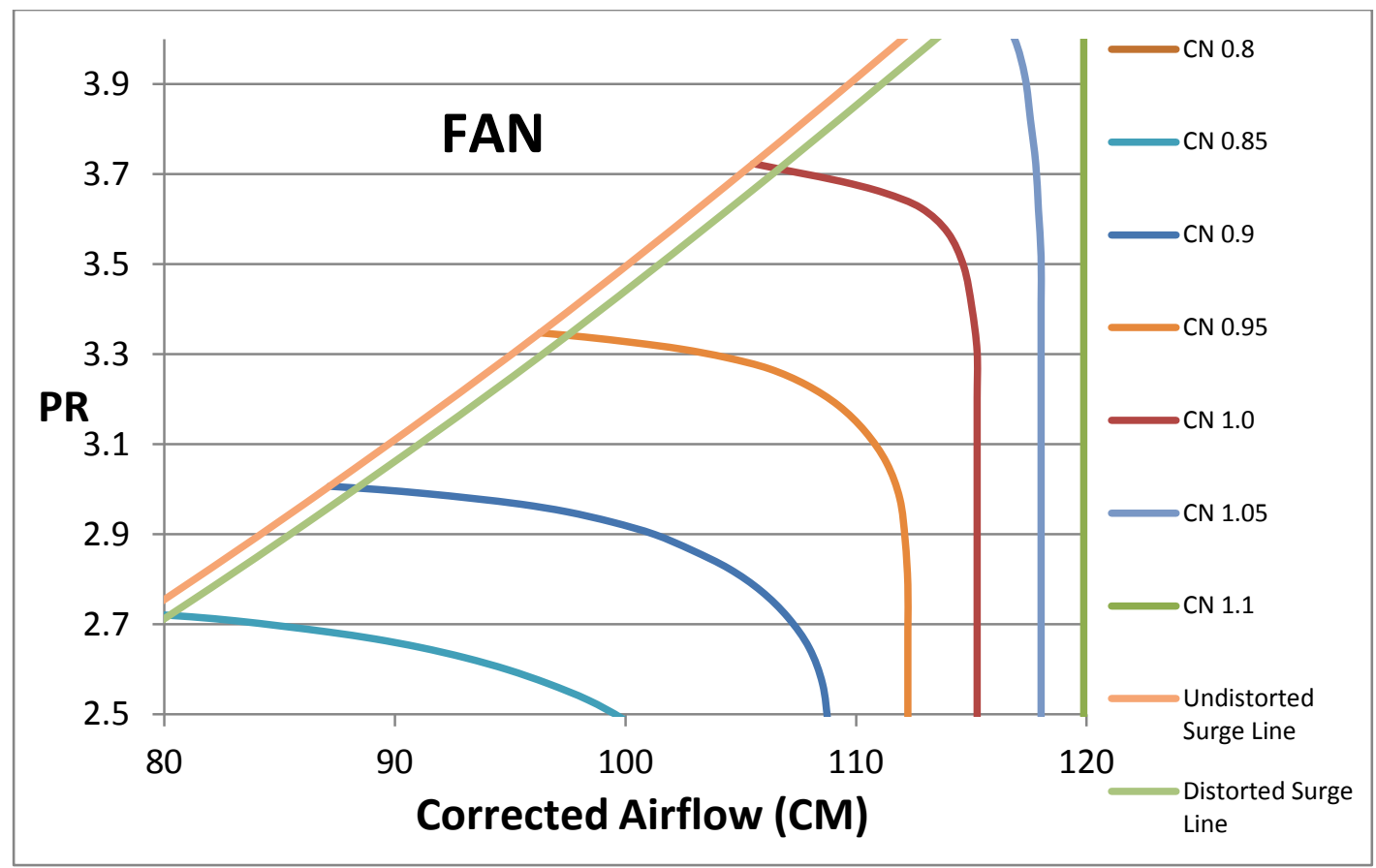

(b)

Fig. 6 FAN Map Showing the Distorted Surge Line for the 0.85M 0_16 Flight Attitude(a) with an Enlarged Area to Point out the Shift of the Lines (b)

\section{CONCLUSIONS}

The present work demonstrates a methodology to assess the effects of distortion on the stability of a fan, given its operating characteristics in terms of a fan map.

When the fan studied herein is concerned:

- $\quad$ None of the 27 examined flight attitudes threatened its stability i.e. the surge margin was not depleted as a result of the airflow distortion due to the examined aircraft flight attitudes.

- The operation of the fan seemed to be quite immune to the distorted inflow conditions caused by these specific flight attitudes since in all examined flight attitudes the resulted total pressure distortion level was not even close to the point where it may cause the surge of the fan.

- In the flight attitude of $0.85 \mathrm{M}$ with $0^{\circ} \mathrm{AOA}$ and $16^{\circ}$ AOSS the induced total pressure distortion caused a shift of the fan surge line towards the direction of surge margin depletion.

- Among the tested cases, this specific flight attitude presented the highest value of $\triangle P R S$ (1.544). When interpreting this value, this flight attitude caused a depletion of the fan surge margin and the percentage difference comparing to the DP value of the $\mathrm{SM}$, is about $7 \%$.

\section{REFERENCES}

1. Kevin R. Walsh, Andrew J. Yuhas, John G. Williams, William G. 
Steenken, 1997, Inlet Distortion for an F/A-18A Aircraft During Steady Aerodynamic Conditions up to $60^{\circ}$ Angle of Attack, NASA Technical Memorandum 104329.

2. Stefan Kennedy, Theresa Robinson, Stephen Spence, 2014, Computational Investigation of Inlet Distortion at High Angles of Attack, JOURNAL OFAIRCRAFT, Vol. 51,No. 2,March-April 2014.

3. Mehalic M. C., 1988, Effect of Spatial Inlet Temperature and Pressure Distortion on Turbofan Engine Stability, NASA-TM-100850.

4. Voytovych D., Merkle C., Xia G., 2010, Effects of Radial Distortion on Performance of a Fan, AIAA 2010-745.

5. Justin M. Bailey, Walter F. O'Brien, 2013, The Influence of Duct Development Distance on Screen Generated Total Pressure Distortion Profiles, 49th AIAA/ASME/SAE/ASEE Joint Propulsion Conference, July 14 17, 2013, San Jose, CA.

6. Reid C., 1969, The Response of Axial Flow Compressors to Intake Flow Distortion, THE AMERICAN SOCIETY OF MECHANICAL ENGINEERS, ASME Paper 69-GT-29.

7. Pearson, $H$. and McKenzie, A.B., 1959, Wakes in Axial Compressors, Journal of the Royal Aeronautical Society, 63, July, pp. 415416.

8. Kurzke J., 2008, Effects of Inlet Flow Distortion on the Performance of Aircraft Gas Turbines, Journal of Engineering for Gas Turbines and Power, 130, July 2008.
9. Davis M., Hale Al., Beale D., 2002, An Argument for Enhancement of the Current Inlet Distortion Ground Test Practice for Aircraft Gas Turbine Engines, Journal of Turbomachinery, Vol. 124, pp 235-241, April 2002.

10. Williams D., 1986, Review of Current Knowledge on Engine Response to Distorted Inflow Conditions, AGARD-CP-400.

11. SAE, 2002, Gas Turbine Engine Inlet Flow Distortion Guidelines, SAE ARP 1420, Rev B, 2002-02.

12. Technical Committee S-16, 1983, Inlet Total Pressure Distortion Considerations for Gas Turbine Engines, SAE AIR 1419, May 1983, (revised 2013).

13. T. Triantafyllou, T. Nikolaidis, M. Diakostefanis, 2016, Effect of Inlet Flow Distortion on Installed Gas Turbine Performance, Accepted as ISABE 2017 conference paper, ISABE, Paper ID 21336.

14. Triantafyllou T., Nikolaidis T., Diakostefanis M., Pilidis P., 2016, Numerical Simulation of the Airflow over a Military Aircraft with Active Intake, Proceedings of the Institution of Mechanical Engineers, Part G: Journal of Aerospace Engineering, SAGE Publications.

15. Palmer J. R., 1990, The TURBOMATCH Scheme For Aero/Industrial Gas Turbine Engine Design Point/Off Design Performance Calculation, SME, Thermal Power Group, Cranfield University.

16. Nikolaidis Th \& Pilidis P, 2014, The effect of water ingestion on an 
axial flow compressor performance, Proceedings of the Institution of Mechanical Engineers Part G-Journal of Aerospace Engineering, 2014, Vol. 228(3) 411-423.

17. Li, Y. G., Marinai, L., Gatto, E. L., Pachidis, V., and Pilidis, P., 2009, Multiple-Point Adaptive Performance Simulation Tuned to Aeroengine TestBed Data, Journal of Propulsion and Power, Vol. 25, (3), 2009, pp. 635-641.

18. Giannakakis P., Laskaridis P., Nikolaidis T., and Kalfas A., 2015, Toward a Scalable Propeller Performance Map, AIAA / Journal of Propulsion and Power, (2015) 31:4, 1073-1082, doi: 10.2514/1.B35498.

19. Jane's AERO-ENGINES, 2007, Issue 21, Jane's Information Group.

20. A. S. Lee, R. Singh, S. D . Probert, 2009, Modeling of the Performance of a F100-PW-229 Equivalent Engine under Sea-level Static Conditions, 45th AIAA/ASME/SAE/ASEE Joint Propulsion Conference \& Exhibit, AIAA 20095018.

21. Triantafyllou T., Nikolaidis T., Diakostefanis M., Pilidis P., 2015, Total Pressure Distortion Levels at the Aerodynamic Interface Plane of a Military Aircraft, The Aeronautical Journal, Volume 119 No 1219, September 2015. 
2017-06-27

\section{Stability assessment of an airflow pÿdistorted military engine s FAN}

\section{Triantafyllou, Theodoros}

SAGE

Triantafyllou T, Nikolaidis T, Diakostefanis M, Pilidis P, Stability assessment of an airflow pÿdistorted military engine s FAN, Proceedings of the Institution of Mechanical Engineers, Part G:

Journal of Aerospace Engineering, Volume: 232 issue: 13, pp. 2584-2592

http://dx.doi.org/10.1177/0954410017716478

Downloaded from Cranfield Library Services E-Repository 